\title{
In silico trials using Monte Carlo simulation to evaluate ciprofloxacin and levofloxacin dosing in critically ill patients receiving prolonged intermittent renal replacement therapy
}

\author{
Susan J. Lewis ${ }^{1}$, Weerachai Chaijamorn², Alexander R. Shaw ${ }^{3}$ and Bruce A. Mueller ${ }^{3 *}$
}

\begin{abstract}
Background: Prolonged intermittent renal replacement therapy (PIRRT) is a growing option to treat acute kidney injury in critically ill patients, but absent pharmacokinetic data challenge optimal drug dosing. Inappropriate antibiotic dosing can cause widespread bacterial resistance and decreased antibiotic utility. The purpose of this study was to evaluate probability of target attainment (PTA) of various ciprofloxacin and levofloxacin regimens in critically ill patients receiving PIRRT, utilizing Monte Carlo simulation (MCS).

Methods: The models incorporated published body weights and pharmacokinetic parameters (volume of distribution, non-renal clearance, and extraction coefficients) and their associated variability and ranges. Four different PIRRT effluent/duration combinations ( $4 \mathrm{~L} / \mathrm{h} \times 10 \mathrm{~h}$ or $5 \mathrm{~L} / \mathrm{h} \times 8 \mathrm{~h}$ in hemodialysis or hemofiltration, respectively) occurring at the beginning or 14-16 $\mathrm{h}$ after drug administration were modeled. MCS predicted drug disposition during the first $72 \mathrm{~h}$ in 5000 virtual patients for each dosing regimen. Desired pharmacodynamic targets to calculate PTA were the 24-h area under the curve/minimum inhibitory concentration (AUC $24 \mathrm{~h}: M I C$ ) of $\geq 125$ and $\geq 50$ for Gram-negative and Gram-positive infections, respectively. The "successful" doses were the ones with PTA of $\sim 90 \%$ in all PIRRT settings.

Results: No conventional, FDA-approved regimens attained $~ 90 \%$ of PTA for Gram-negative infection with Pseudomonas aeruginosa at the MIC of 1 and $2 \mathrm{mg} / \mathrm{L}$ for ciprofloxacin and levofloxacin, respectively. The successful doses (ciprofloxacin $1200 \mathrm{mg}$ loading dose, $800 \mathrm{mg}$ q12h, and levofloxacin $2000 \mathrm{mg}$ loading dose, $1000 \mathrm{mg}$ q24h post-PIRRT) greatly exceed the maximum FDA-approved doses. For Gram-positive infections, a levofloxacin $750 \mathrm{mg}$ loading dose and $500 \mathrm{mg}$ q24h post-PIRRT successfully attained PTA 90 \% at the MIC of $1 \mathrm{mg} / \mathrm{L}$ for Streptococcus pneumoniae.

Conclusions: Ciprofloxacin and levofloxacin cannot be recommended as empiric monotherapy for serious Gramnegative infections in patients receiving PIRRT due to suboptimal efficacy. This MCS prediction supports rational dosing decisions to treat infected patients receiving PIRRT and should be used until clinical pharmacokinetic trials are conducted in this population.
\end{abstract}

Keywords: Ciprofloxacin, In silico modeling, Levofloxacin, Monte Carlo simulation, Prolonged intermittent renal replacement therapy, Pharmacodynamics, Pharmacokinetics

\footnotetext{
*Correspondence: muellerb@med.umich.edu

${ }^{3}$ Department of Clinical Pharmacy, University of Michigan College of

Pharmacy, 428 Church Street, Ann Arbor, Ml 48109, USA

Full list of author information is available at the end of the article
} 


\section{Background}

Prolonged intermittent renal replacement therapy (PIRRT) is a hybrid RRT used in the critical care setting as an alternative to conventional RRTs like intermittent hemodialysis (IHD) or continuous renal replacement therapy (CRRT). The typical duration of PIRRT is $6-12 \mathrm{~h}$, providing the benefits of better patient mobility and less cost compared to CRRT, but a longer treatment period with slower flow rates which allows for better tolerated fluid removal than IHD [1-6]. With these unique qualities and similar patient outcomes compared to conventional RRT, more clinicians are considering PIRRT as a viable treatment option for acute kidney injury in critically ill patients [1-7]. However, very few antibiotic pharmacokinetic studies have been conducted in patients receiving PIRRT, prompting one set of authors to opine that PIRRT is a rational RRT that does not allow for rational drug dosing [8]. Indeed, validated PIRRT dosing recommendations are available for less than $1 \%$ of drugs [8], and there is a growing understanding that inappropriate empiric antibiotic dosing is associated with poor clinical outcomes in critically ill patients $[9,10]$. More than $70 \%$ of critically ill patients receive antibiotics, and the primary mortality cause in these patients is infection [11]. With emerging bacterial resistance and lack of novel antibiotic development, clinicians are more pressured than ever to ensure that they are using appropriate antibiotic doses to maximize bacterial eradication while ensuring safe use. Hence, more pharmacokinetic studies are urgently needed to ensure rational antibiotic dosing in patients receiving PIRRT. Clinical trials are indispensable to establish antibiotic dosing recommendations; however, clinical trials are often not feasible. Clinical trials are expensive, and the FDA does not mandate drug or RRT device companies to conduct pharmacokinetic trials in PIRRT. The operating characteristics of PIRRT (duration, convective and diffusive modalities, and effluent flow rates) vary widely; consequently, drug dosing may vary as well. This makes it unlikely that sufficient PIRRT pharmacokinetic trials will ever be conducted in these vulnerable patients. Alternative approaches to clinical trials are needed to develop appropriate dosing in PIRRT. For decades, in silico trials using Monte Carlo simulation (MCS) have been used to determine optimal drug regimens during drug discovery and development. This approach has been employed to predict optimal antibiotic doses in patients with IHD and CRRT $[12,13]$, but not with PIRRT. Antibiotic dosing in patients with PIRRT is challenging, because dosing must take into account the pharmacokinetics altered not only by critical illness and but also by the timing of PIRRT and its associated drug clearance in relation to drug administration [14]. However, in silico trials can integrate our current understanding of PIRRT's influence on drug disposition and can inform appropriate antibiotic dosing in this patient population with limited available pharmacokinetic data generated from more conventional sources like clinical trials.

Ciprofloxacin and levofloxacin are fluoroquinolone antibiotics, often prescribed to treat moderate to severe infections in critically ill patients. They exert concentrationdependent bactericidal activity against most Gram-negative aerobic pathogens and some Gram-positive organisms. However, the widespread dissemination of fluoroquinolone resistance among key pathogens can limit their use $[15,16]$. For example, fluoroquinolone resistance rates in Gramnegative bacilli species such as Pseudomonas aeruginosa in ICUs have more than doubled from $11 \%$ in 1990-1993 to $27.4 \%$ in 2011 [16, 17]. The decline of fluoroquinolone activity may be the most concerning of all antibiotic resistance patterns among Gram-negative pathogens in the ICU. The emergence of fluoroquinolone resistance among many Gram-positive pathogens has also reduced its clinical utility in the ICU $[18,19]$. Frequent prescribing and suboptimal dosing contributed to this alarming trend $[9,20]$. Previous studies indicated that the 24-h area under the curve $\left(\mathrm{AUC}_{24 \mathrm{~h}}\right)$ :minimum inhibitory concentration $(\mathrm{MIC})$ ratio is the pharmacodynamic parameter most predictive of fluoroquinolone efficacy [21]. A total $\mathrm{AUC}_{24 \mathrm{~h}}: \mathrm{MIC} \geq 125$ has been correlated with optimal clinical outcomes in critically ill patients infected with Gram-negative pathogens including $P$. aeruginosa [22], while a lower target of a total $\mathrm{AUC}_{24 \mathrm{~h}}$ :MIC $\geq 50$ is sufficient to treat Gram-positive pathogens such as S. pneumoniae [23]. Fluoroquinolone-associated toxicities are mild-to-moderate in most cases. However, fluoroquinolone-associated cardiovascular toxicity (i.e., prolongation of QT interval) that can potentially lead to lifethreatening torsades de pointes $[24,25]$ is a rising concern, especially in high-risk patient populations such as critically ill patients who may require higher doses. Central nervous system (CNS) adverse effects may be commonly observed with fluoroquinolone therapy, especially in patients with a previous CNS impairment [26]. The risk factors are likely patient-specific, but it is suggested that dosing regimens should not exceed the FDA-approved doses to prevent these toxicities [25]. Currently, no ciprofloxacin pharmacokinetic studies have been published in PIRRT. Levofloxacin has been evaluated in one small study $(n=5)$ with extended daily dialysis, one type of PIRRT, but the optimal dosing has not been determined [27]. With this lack of available pharmacokinetic dosing data, pharmacist-recommended fluoroquinolone doses in patients receiving PIRRT vary extensively, with up to fivefold dosing differences being proposed [28]. The objective of the present study was to predict the likelihood of pre-defined pharmacodynamic target attainment in intravenous ciprofloxacin and levofloxacin dosing regimens as empiric treatment for serious Gram-negative infections in virtual patients receiving daily PIRRT using MCS techniques. Additionally, intravenous 
levofloxacin dosing regimens were also evaluated for treatment of Gram-positive infections.

\section{Methods}

\section{Pharmacokinetic model development}

The model integrated relevant input parameters to construct a realistic virtual patient population, as outlined in Table 1. Body weight was derived from a large PIRRT study [4] and pharmacokinetic data from published ciprofloxacin and levofloxacin pharmacokinetic studies in critically ill patients receiving RRT [29-36]. In order to avoid spurious simulations, limits were obtained from those previous studies and were set for all input parameters. Body weight lower limits were set at $\geq 40 \mathrm{~kg}$ assuming that the virtual patients are adults [4]. The ranges of volume of distribution $\left(V_{\mathrm{d}}\right)$ and non-renal clearance values $\left(\mathrm{CL}_{\mathrm{NR}}\right)$ were extracted from the relevant ciprofloxacin and levofloxacin pharmacokinetic studies [29-36]. The correlation (i.e., coefficient of determination, $r^{2}$ ) between body weight and $V_{\mathrm{d}}$ or $\mathrm{CL}_{\mathrm{NR}}$ were also derived from those previous studies and integrated into the models to construct realistic pharmacokinetic parameters. The relationship between these parameters was found to be not significant except for that between body weight and $\mathrm{CL}_{\mathrm{NR}}$ for levofloxacin [33]. Transmembrane RRT drug clearance was calculated by multiplying effluent flow rate (dialysate $\left(Q_{\mathrm{d}}\right)$ and/or ultrafiltrate flow rate $\left(Q_{\mathrm{uf}}\right)$ ) by the extraction coefficient (also called sieving coefficient for hemofiltration and saturation coefficient for hemodialysis) which is the percentage of drug that crosses the hemodiafilter membrane. For sieving/saturation coefficients, the upper limit was set at 1 . The model integrated four commonly employed PIRRT settings, using two different effluent flow rates/durations in hemodialysis and hemofiltration modes. They were as follows: (1) hemofiltration mode with $Q_{\text {uf }}$ of $4 \mathrm{~L} / \mathrm{h}$ for $10 \mathrm{~h} /$ day, (2) hemofiltration mode with $Q_{u f}$ of $5 \mathrm{~L} / \mathrm{h}$ for $8 \mathrm{~h} /$ day, (3) hemodialysis mode with $Q_{\mathrm{d}}$ of $4 \mathrm{~L} / \mathrm{h}$ for $10 \mathrm{~h} /$ day, and (4) hemodialysis mode with $Q_{d}$ of $5 \mathrm{~L} / \mathrm{h}$ for $8 \mathrm{~h} /$ day. Blood flow rate was set at $300 \mathrm{~mL} / \mathrm{min}$ in all PIRRT settings. For hemofiltration mode, all replacement fluid was modeled to be administered using the pre-dilution mode as used commonly in clinical practice. The equations used in the model were following:

$$
\begin{array}{ll}
\mathrm{CL}_{\mathrm{HD}}(\mathrm{L} / \mathrm{h})=\mathrm{SA} * Q_{\mathrm{d}} & \\
\mathrm{CL}_{\mathrm{HF}}(\mathrm{L} / \mathrm{h})=\mathrm{SC} * Q_{\mathrm{uf}} *\left[Q_{\text {plasma }} /\left(Q_{\text {plasma }}+Q_{\text {replacement }}\right)\right] \\
V_{\mathrm{d}}(\mathrm{L})=\mathrm{WT} * V_{\mathrm{d}}(\mathrm{L} / \mathrm{kg}) & \\
k_{\mathrm{on}}=\left(\mathrm{CL}_{\mathrm{NR}}+\mathrm{CL}_{\mathrm{HD}}\right) / V_{\mathrm{d}} & \text { (for hemodialysis mode) } \\
k_{\mathrm{on}}=\left(\mathrm{CL}_{\mathrm{NR}}+\mathrm{CL}_{\mathrm{HF}}\right) / V_{\mathrm{d}} & \text { (for hemofiltration mode) } \\
k_{\text {off }}=\mathrm{CL}_{\mathrm{NR}} / V_{\mathrm{d}} &
\end{array}
$$

\section{$[37,38]$}

where $\mathrm{CL}_{\mathrm{HF}}$ is transmembrane clearance in hemofiltration; SC is sieving coefficient; $Q_{u f}$ is ultrafiltrate flow rate; $Q_{\text {plasma }}$ is plasma flow rate $\left(Q_{\text {plasma }}=Q_{\text {blood }}\right.$ ( 1 - hematocrit $)$; hematocrit is $30 \%$ [38]); $Q_{\text {replacement }}$ is replacement fluid flow rate $\left(Q_{\text {replacement }}=Q_{\mathrm{uf}}\right) ; \mathrm{CL}_{\mathrm{HD}}$ is transmembrane clearance in hemodialysis; SA is saturation coefficient; $Q_{\mathrm{d}}$ is dialysate flow rate; $V_{\mathrm{d}}$ is volume of distribution; WT $(\mathrm{kg})$ is body weight; $k_{\mathrm{on}}$ is the elimination rate constant during PIRRT; $\mathrm{CL}_{\mathrm{NR}}$ is non-renal clearance; and $k_{\text {off }}$ is the elimination rate constant off PIRRT.

\section{Monte Carlo simulations}

Pharmacodynamic exposures were modeled using a onecompartment model with constant intravenous input and first-order elimination (Additional file 1). MCS (Crystal Ball Classroom Edition, Oracle) was performed to generate total serum concentration-time profiles, following a previously published method [39]. Twelve different ciprofloxacin and 17 different levofloxacin dosing regimens including those recommended for patients receiving other types of RRT and those for normal kidney function were simulated with infusion time of $1 \mathrm{~h}$ for both agents $[40,41]$. Fluoroquinolone disposition was assessed for the first $72 \mathrm{~h}$ in order to evaluate the relative influences of

Table 1 Input parameters used in in silico ciprofloxacin and levofloxacin dosing trials in PIRRT [30-36]

\begin{tabular}{llr}
\hline & Ciprofloxacin & Levofloxacin \\
\hline Demographic and pharmacokinetic parameters & & \\
Weight $(\mathrm{kg})$ & $86.6 \pm 29.2[\geq 40]$ & $1.2 \pm 0.4[0.7-2.08]$ \\
Volume of distribution $(\mathrm{L} / \mathrm{kg})$ & $1.25 \pm 0.4[0.5-1.92]$ & $25.7 \pm 14[0.12-67]$ \\
Non-renal clearance $(\mathrm{mL} / \mathrm{min})$ & $0.7 \pm 0.2[0-1]$ & $0.6 \pm 0.2[0-1]$ \\
Saturation/sieving coefficient & & Hemofiltration or hemodialysis \\
PIRRT operation parameters & & Daily \\
Modality & & $300 \mathrm{~mL} / \mathrm{min}$ \\
Frequency & & $4 \mathrm{~L} / \mathrm{h}$ for $10 \mathrm{~h}$ or $5 \mathrm{~L} / \mathrm{h}$ for $8 \mathrm{~h}$ \\
Blood flow rate & & \\
Dialysate/ultrafiltration flow rate and duration & & \\
\hline
\end{tabular}

All values are represented as mean \pm SD [assigned model limits] 
loading and maintenance doses even in the extended dosing intervals (e.g., $48 \mathrm{~h}$ ). In clinical practice, fluoroquinolone doses can be administered at the beginning of, or during the middle of PIRRT, or several hours prior to a PIRRT session. In order to consider all clinical situations, we simulated each fluoroquinolone dosing regimen in the two most extreme scenarios in each of four PIRRT settings. One scenario was when the PIRRT is commenced at the beginning of first fluoroquinolone dose infusion (early PIRRT), and the other scenario was when PIRRT occurred 14 or $16 \mathrm{~h}$ after the first fluoroquinolone dose is administered (late PIRRT).

\section{Probability of target attainment prediction}

The pharmacodynamic targets used in these in silico trials were $\mathrm{AUC}_{24 \mathrm{~h}} \mathrm{MIC} \geq 125$ for each $24 \mathrm{~h}$ period during the initial $72 \mathrm{~h}$ therapy for Gram-negative infections and $\mathrm{AUC}_{24 \mathrm{~h}}: \mathrm{MIC} \geq 50$ for Gram-positive infections [23, 24]. $\mathrm{AUC}_{24 \mathrm{~h}}$ was calculated by $24-\mathrm{h}$ area under the curve using the linear trapezoidal formula. The reference Gram-negative pathogen was $P$. aeruginosa which is associated with the increased mortality rates in the ICUs [42]. Based on the Clinical and Laboratory Standards Institute, the clinical breakpoint of $P$. aeruginosa is $1 \mathrm{mg} / \mathrm{L}$ for ciprofloxacin and $2 \mathrm{mg} / \mathrm{L}$ for levofloxacin [43]. For Gram-positive infection simulations, S. pneumoniae was chosen and its clinical breakpoint for levofloxacin is $2 \mathrm{mg} / \mathrm{L}$ [43]. Probability of target attainment (PTA) was calculated by summing up the virtual patient numbers achieving the pre-defined pharmacodynamic target and dividing by the total number of patients $(n=5000)$. In addition, PTA of each dosing regimen was calculated at doubling MIC dilutions ranging from 0.25 to $4 \mathrm{mg} / \mathrm{L}$. If a regimen yielded $\sim 90 \%$ of PTA in all PIRRT settings regardless of the time of PIRRT institution in relation to the first drug administration using the smallest daily dose, the dosing regimen was considered "successful." However, benefits of achieving the pharmacodynamic target had to be weighed against the risk of drug toxicity. No published studies are available to clearly define fluoroquinolone exposure and a toxicity concentration threshold. Given that these patients with PIRRT are more vulnerable to experience fluoroquinolone-associated cardiovascular and CNS toxicities that can be life-threatening, we decided a priori that any dosing recommendation would not exceed within the FDA-approved intravenous doses $(1200 \mathrm{mg} /$ day for ciprofloxacin and $750 \mathrm{mg} /$ day for levofloxacin) due to safety concerns $[25,40,41]$.

\section{Sensitivity analyses}

Sensitivity analyses were performed to investigate the influence of different PIRRT operational settings on fluoroquinolone clearance by PIRRT. As mentioned, fluoroquinolone dosing regimens in early vs. late PIRRT were compared to assess whether "when" to give a drug in relation to PIRRT substantially impacted PTA. Many other RRT-specific factors can affect extracorporeal drug clearance. However, where blood flow rate is much higher than effluent flow rate (like the PIRRT settings in our model), the effluent flow rate is the most important covariate to determine extracorporeal drug clearance in RRT [44]. Consequently, we re-evaluated PTA of the successful fluoroquinolone dosing regimens from this present study in a wide array of effluent flow rates ranging from 2 to $10 \mathrm{~L} / \mathrm{h}$ using the same treatment duration. Sensitivity analyses were performed for all successful ciprofloxacin and levofloxacin doses for serious Gramnegative infection in 8- and 10-h hemofiltration treatments. Sensitivity analyses could not be performed in hemodialysis experiments because of limited published extraction coefficient data in hemodialysis at varying dialysate flow rates.

\section{Results}

Tables 2 and 3 summarize the PTA results of selected ciprofloxacin and levofloxacin dosing regimens to treat Gram-negative infections with $P$. aeruginosa and Grampositive infections with $S$. pneumoniae, respectively, during the initial $72 \mathrm{~h}$ of therapy in both early and late PIRRT settings. The PTA difference in early or late PIRRT only ranged $1-2 \%$ among the four different RRT settings in simulation results. Thus, the results of the 8$\mathrm{h}$ hemodialysis PIRRT were presented as representative examples of the other RRT settings. None of the clinically used ciprofloxacin and levofloxacin dosing regimens, including the FDA-approved maximum doses for patients with normal renal function, attained $\sim 90 \%$ of PTA as treatment of Gram-negative infection with $P$. aeruginosa. The approved maximal doses of intravenous ciprofloxacin for patients with normal renal function (400 mg q8h) attained PTAs of only 30, 70-71, and $76 \%$ on days 1,2 , and 3 , respectively. For levofloxacin, $750 \mathrm{mg}$ q24h yielded only 10, 25-44, and $46-64 \%$ on days 1,2 , and 3 , respectively. The simulation results predicted that ciprofloxacin regimen of $1200 \mathrm{mg}$ loading dose (LD), then $800 \mathrm{mg} \mathrm{q} 12 \mathrm{~h}$, and levofloxacin regimen of $2000 \mathrm{mg}$ loading dose, then $1000 \mathrm{mg}$ q24h postPIRRT, would be required to attain PTA of $~ 90 \%$ or greater to treat Gram-negative infections with $P$. aeruginosa regardless of the time of daily PIRRT institution. For Gram-positive infections, however, the levofloxacin regimen of $750 \mathrm{mg} \mathrm{LD}$, then $500 \mathrm{mg}$ q24h post-PIRRT, successfully met $\sim 90 \%$ PTA. Substantial differences of PTA in early vs. late PIRRT were only observed in levofloxacin trials, likely because of its longer (q24h-q48h) dosing intervals (Tables 2 and 3). Figure 1 illustrates the PTA at $\mathrm{AUC}_{24 \mathrm{~h}}: \mathrm{MIC} \geq 125$ for selective ciprofloxacin and levofloxacin dosing regimens at specific MICs in early and late PIRRT to treat Gram-negative infections. Figure 2 depicts the PTA at $\mathrm{AUC}_{24 \mathrm{~h}}$ :MIC $\geq 50$ for 
Table 2 Probability of target attainment of selected ciprofloxacin and levofloxacin dosing regimens for Gram-negative infection with P. aeruginosa in 5000 virtual patients with 8-h hemodialysis PIRRT at dialysate flow rate of $5 \mathrm{~L} / \mathrm{h}$ during the initial $72 \mathrm{~h}$

\begin{tabular}{|c|c|c|c|c|c|c|c|c|}
\hline \multirow[t]{2}{*}{ Dosing regimens } & \multicolumn{4}{|c|}{ Early PIRRT ${ }^{\mathrm{b}}$} & \multicolumn{4}{|c|}{ Late PIRRT ${ }^{c}$} \\
\hline & $\begin{array}{l}\text { Day } 1 \\
\text { PTA (\%) }\end{array}$ & $\begin{array}{l}\text { Day } 2 \\
\text { PTA (\%) }\end{array}$ & $\begin{array}{l}\text { Day } 3 \\
\text { PTA (\%) }\end{array}$ & $\begin{array}{l}\text { Mean } \\
\text { PTA (\%) }\end{array}$ & $\begin{array}{l}\text { Day } 1 \\
\text { PTA (\%) }\end{array}$ & $\begin{array}{l}\text { Day } 2 \\
\text { PTA (\%) }\end{array}$ & $\begin{array}{l}\text { Day } 3 \\
\text { PTA (\%) }\end{array}$ & $\begin{array}{l}\text { Mean } \\
\text { PTA (\%) }\end{array}$ \\
\hline \multicolumn{9}{|l|}{ Ciprofloxacin } \\
\hline $200 \mathrm{mg} \mathrm{q12h}$ & 0.0 & 0.0 & 0.0 & 0.0 & 0.0 & 0.3 & 0.6 & 0.1 \\
\hline $400 \mathrm{mg} \mathrm{q} 12 \mathrm{~h}$ & 3.9 & 24.3 & 33.4 & 17.3 & 7.8 & 30.0 & 38.0 & 23.8 \\
\hline $800 \mathrm{mg} \mathrm{q12h}$ & 66.6 & 91.2 & 92.5 & 87.9 & 72.5 & 92.6 & 93.7 & 90.1 \\
\hline $200 \mathrm{mg}$ q8h & 0.3 & 5.8 & 11.2 & 3.5 & 0.4 & 5.5 & 10.5 & 3.5 \\
\hline $400 \mathrm{mg}$ q8h & 27.7 & 71.0 & 76.2 & 62.2 & 30.1 & 70.3 & 75.6 & 63.3 \\
\hline $600 \mathrm{mg} \mathrm{q} 8 \mathrm{~h}$ & 75.4 & 96.1 & 96.9 & 93.9 & 76.3 & 96.2 & 96.9 & 94.3 \\
\hline $1200 \mathrm{mg}$ LD, then $800 \mathrm{mg} \mathrm{q} 12 \mathrm{~h}$ & 89.9 & 92.3 & 92.7 & 92.9 & 93.1 & 94.2 & 94.4 & 94.8 \\
\hline \multicolumn{9}{|l|}{ Levofloxacin } \\
\hline 750 mg q24h & 1.7 & 25.4 & 45.9 & 24.4 & 9.9 & 43.5 & 63.5 & 39.0 \\
\hline $\begin{array}{l}750 \mathrm{mg} \text { LD, then } 250 \mathrm{mg} \text { q24h } \\
\text { post-PIRRT }\end{array}$ & 11.1 & 3.6 & 1.7 & 5.5 & 10.0 & 3.1 & 1.6 & 4.9 \\
\hline $\begin{array}{l}750 \mathrm{mg} \text { LD, then } 500 \mathrm{mg} \text { q24h } \\
\text { post-PIRRT }\end{array}$ & 27.4 & 32.0 & 35.0 & 31.5 & 10.4 & 20.8 & 28.6 & 20.0 \\
\hline $\begin{array}{l}750 \mathrm{mg} \text { LD, then } 750 \mathrm{mg} \text { q24h } \\
\text { post-PIRRT }\end{array}$ & 45.3 & 65.5 & 73.9 & 61.5 & 10.9 & 44.1 & 63.1 & 39.4 \\
\hline $\begin{array}{l}1500 \mathrm{mg} \text { LD, then } 750 \mathrm{mg} \text { q24h } \\
\text { post-PIRRT }\end{array}$ & 83.7 & 84.2 & 83.4 & 83.8 & 66.3 & 74.1 & 77.6 & 72.7 \\
\hline $\begin{array}{l}1500 \mathrm{mg} \text { LD, then } \\
1000 \mathrm{mg} \text { q24h post-PIRRT }\end{array}$ & 89.2 & 93.8 & 95.3 & 92.8 & 67.2 & 84.8 & 91.4 & 81.2 \\
\hline $\begin{array}{l}2000 \mathrm{mg} \text { LD, then } 1000 \mathrm{mg} \mathrm{q} 24 \mathrm{~h} \\
\text { post-PIRRT }\end{array}$ & 96.4 & 97.1 & 96.9 & 96.8 & 87.5 & 92.5 & 94.5 & 91.5 \\
\hline
\end{tabular}

Bolded dosing regimens are the ones that attained PTA of $\sim 90 \%$ or greater in both early and late PIRRT, using the smallest daily dose $L D$ loading dose

a Pharmacodynamic target used for Gram-negative infection was $\mathrm{AUC}_{24 \mathrm{~h}}: \mathrm{MIC} \geq 125$ with MIC $=1 \mathrm{mg} / \mathrm{L}$ for ciprofloxacin and MIC $=2 \mathrm{mg} / \mathrm{L}$ for levofloxacin (susceptibility breakpoint for Pseudomonas aeruginosa)

bEarly PIRRT: when the first fluoroquinolone dose is administered with the commencement of a daily PIRRT session

'Late PIRRT: when the first fluoroquinolone dose is administered $16 \mathrm{~h}$ before a daily PIRRT session

Table 3 Probability of target attainment of selective levofloxacin dosing regimens for Gram-positive infection with S. pneumoniae in 5000 virtual patients with 8-h hemodialysis PIRRT at dialysate flow rate of $5 \mathrm{~L} / \mathrm{h}$ during the initial $72 \mathrm{~h}$

\begin{tabular}{|c|c|c|c|c|c|c|c|c|}
\hline \multirow[t]{2}{*}{ Dosing regimens } & \multicolumn{4}{|c|}{ Early PIRRT ${ }^{b}$} & \multicolumn{4}{|c|}{ Late PIRRT ${ }^{c}$} \\
\hline & $\begin{array}{l}\text { Day } 1 \\
\text { PTA (\%) }\end{array}$ & $\begin{array}{l}\text { Day } 2 \\
\text { PTA }(\%)\end{array}$ & $\begin{array}{l}\text { Day } 3 \\
\text { PTA (\%) }\end{array}$ & $\begin{array}{l}\text { Mean } \\
\text { PTA (\%) }\end{array}$ & $\begin{array}{l}\text { Day } 1 \\
\text { PTA (\%) }\end{array}$ & $\begin{array}{l}\text { Day } 2 \\
\text { PTA (\%) }\end{array}$ & $\begin{array}{l}\text { Day } 3 \\
\text { PTA (\%) }\end{array}$ & $\begin{array}{l}\text { Mean } \\
\text { PTA (\%) }\end{array}$ \\
\hline \multicolumn{9}{|l|}{ Levofloxacin } \\
\hline 500 mg q48h & 33.2 & 0.0 & 66.0 & 33 & 50.0 & 0.0 & 76.8 & 43.5 \\
\hline 500 mg q24h & 32.4 & 82.3 & 93.6 & 69.4 & 49.2 & 87.7 & 96.3 & 77.7 \\
\hline $\begin{array}{l}750 \mathrm{mg} \text { LD, then } 250 \mathrm{mg} \mathrm{q} 24 \mathrm{~h} \\
\text { post-PIRRT }\end{array}$ & 90.3 & 85.5 & 78.4 & 84.7 & 82.4 & 78.4 & 73.9 & 78.3 \\
\hline $\begin{array}{l}750 \mathrm{mg} \text { LD, then } 500 \mathrm{mg} \mathrm{q} 24 \mathrm{~h} \\
\text { post-PIRRT }\end{array}$ & 96.2 & 98.3 & 99.0 & 97.8 & 83.6 & 94.6 & 97.7 & 91.9 \\
\hline $\begin{array}{l}750 \mathrm{mg} \text { LD, then } 750 \mathrm{mg} \mathrm{q} 24 \mathrm{~h} \\
\text { post-PIRRT }\end{array}$ & 98.8 & 99.9 & 99.9 & 99.6 & 84.1 & 98.8 & 99.9 & 94.3 \\
\hline
\end{tabular}

Bolded dosing regimens are the ones that attained PTA of $\sim 90 \%$ or greater in both early and late PIRRT, using the smallest daily dose

LD loading dose

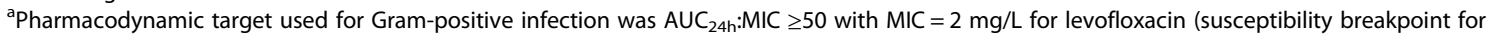

Streptococcus pneumoniae)

${ }^{b}$ Early PIRRT: when the first fluoroquinolone dose is administered with the commencement of a daily PIRRT session

'Late PIRRT: when the first fluoroquinolone dose is administered $16 \mathrm{~h}$ before a daily PIRRT session 


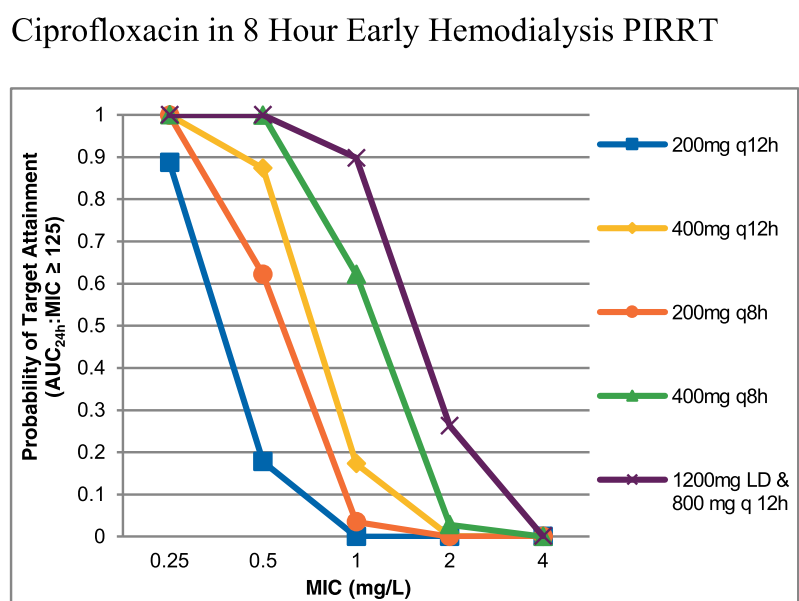

Ciprofloxacin in 8 Hour Late Hemodialysis PIRRT

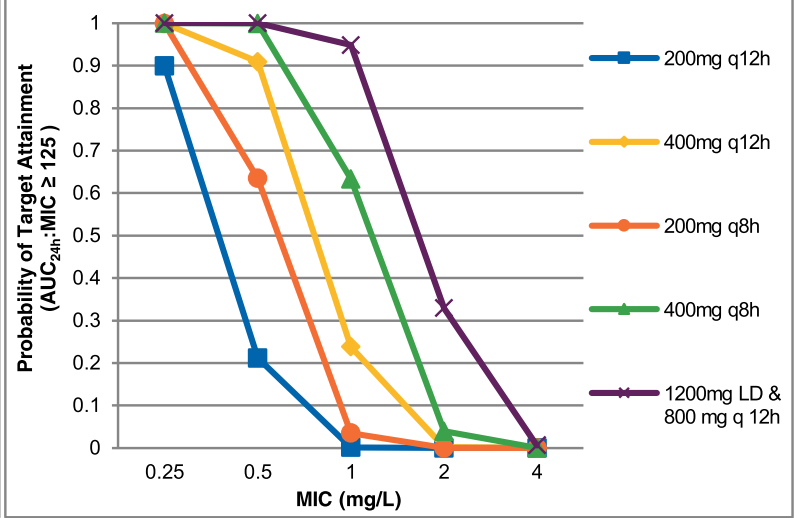

Levofloxacin in 8 Hour Early Hemodialysis PIRRT

Levofloxacin in 8 Hour Late Hemodialysis PIRRT
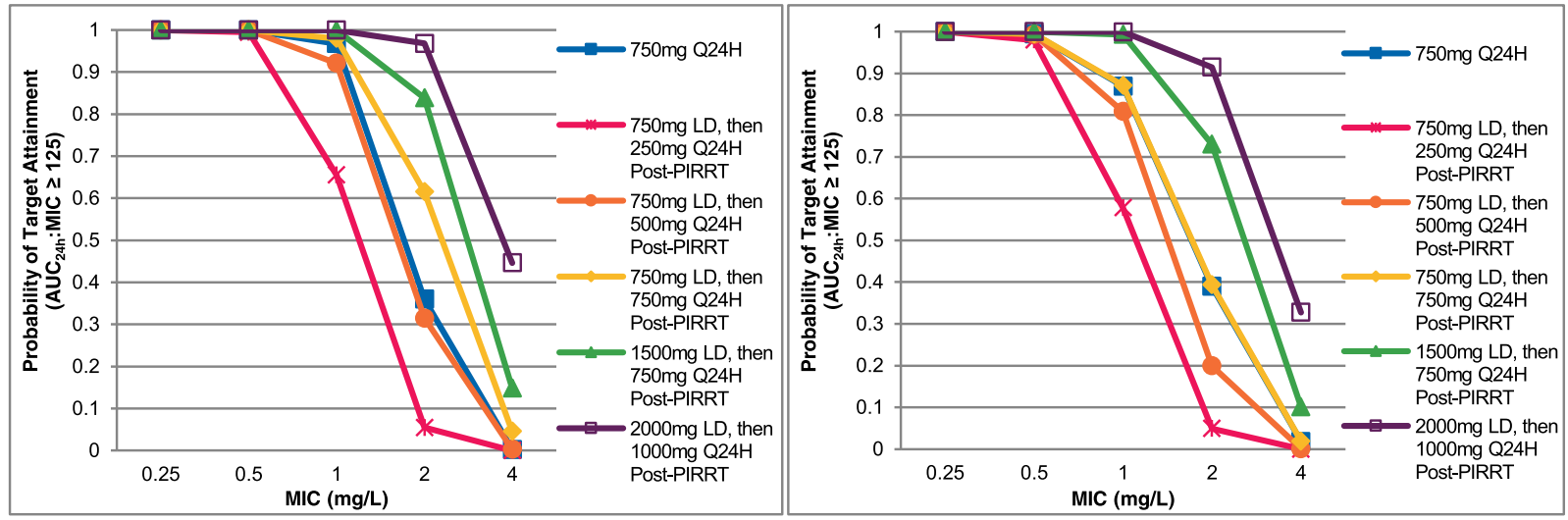

Fig. 1 PTA of ciprofloxacin/levofloxacin regimens at different MICs in virtual patients with Gram-negative infection in PIRRT. Early PIRRT is when the first intravenous ciprofloxacin or levofloxacin dose is administered with the commencement of an 8-h daily PIRRT session. Late PIRRT is when the first intravenous fluoroquinolone dose is administered $16 \mathrm{~h}$ before a daily 8-h PIRRT session. The PTA results were the average of PTA on each $24 \mathrm{~h}$ period during the initial $72 \mathrm{~h}$ therapy in virtual patients with 8-h hemodialysis PIRRT with $5 \mathrm{~L} / \mathrm{h}$ of dialysate flow rate

selective levofloxacin dosing regimens at specific MICs for treatment of Gram-positive infections. The additional information on PTA of selected ciprofloxacin and levofloxacin dosing regimens in the other three PIRRT settings is provided as Additional files 2 and 3. Table 4 depicts results of further sensitivity analyses with respect to effluent flow rates. Employment of different effluent flow rates of the same treatment duration did not yield substantially different PTAs of the fluoroquinolone dosing regimens from this present study in 8-h hemofiltration PIRRT. Sensitivity analyses of the other studied flow rates are nearly identical.

\section{Discussion}

This is the first in silico trial using MCS to evaluate various fluoroquinolone dosing regimens to treat critically ill patients with PIRRT. This approach permits incorporation of the commonly used PIRRT settings into the models with existing demographic and pharmacokinetic parameters published from critically ill patients receiving RRT to predict fluoroquinolone serum concentrations in patients receiving PIRRT. The MCS tested the PTA of various fluoroquinolone regimens in a large virtual cohorts $(n=$ 5000) who had the same variability in their personal pharmacokinetic profiles as has been seen in the published fluoroquinolone pharmacokinetic literature conducted in critically ill patients. These in silico trials illustrate that MCS can be highly useful and a cost-effective approach to assess expected efficacy of various antibiotic dosing regimens and to guide appropriate antibiotic dosing in this special patient population with limited pharmacokinetic data.

The present study predicts that even maximal recommended ciprofloxacin (1200 mg/day) and levofloxacin 


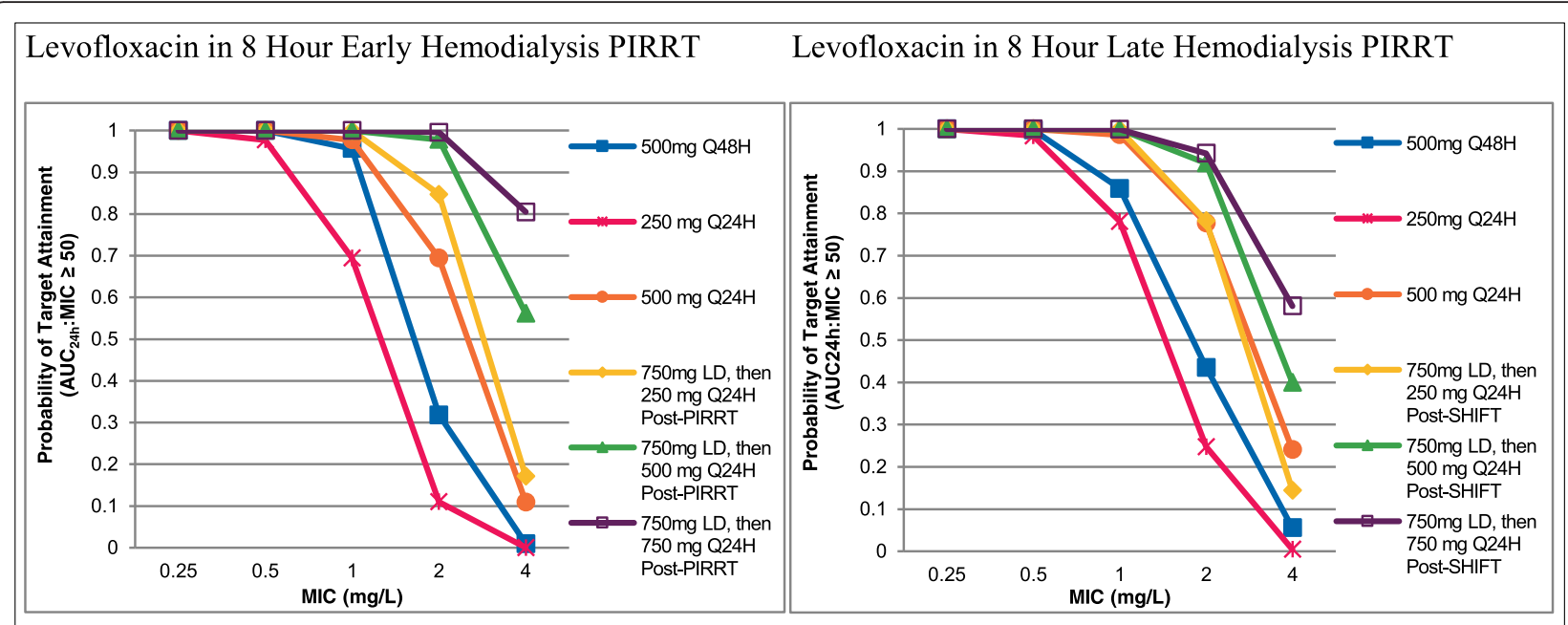

Fig. 2 PTA of levofloxacin regimens at different MICs in virtual patients with Gram-positive infection in PIRRT. Early PIRRT is when the first intravenous levofloxacin dose is administered with the commencement of an 8-h daily PIRRT session. Late PIRRT is when the first intravenous levofloxacin dose is administered $16 \mathrm{~h}$ before a daily 8-h PIRRT session. The PTA results were the average of PTA on each $24 \mathrm{~h}$ period during the initial $72 \mathrm{~h}$ therapy in virtual patients with 8-h hemodialysis PIRRT with $5 \mathrm{~L} / \mathrm{h}$ of dialysate flow rate

(750 mg/day) doses would not yield adequate antibiotic exposure to treat Gram-negative infections with $P$. aeruginosa (MIC of $1 \mathrm{mg} / \mathrm{L}$ for ciprofloxacin and $2 \mathrm{mg} / \mathrm{L}$ for levofloxacin) in most critically ill patients receiving PIRRT. The simulation results indicate that a total of $2000 \mathrm{mg}$ of ciprofloxacin is required on day 1 and $1600 \mathrm{mg}$ for days 2 and 3 to attain the accepted pharmacodynamic target $\left(\mathrm{AUC}_{24 \mathrm{~h}}: \mathrm{MIC} \geq 125\right)$ in $\sim 90 \%$ or greater of virtual patients. For levofloxacin, $2000 \mathrm{mg}$ was required for day 1 and $1000 \mathrm{mg}$ on days 2 and 3. These MCS results are not surprising, because of the growing

Table 4 PTA sensitivity analyses of "successful" fluoroquinolone dosing recommendation with various effluent flow rates in PIRRT

\begin{tabular}{lll}
\hline $\mathrm{AUC}_{24 h: M I C} \mathrm{M}^{\mathrm{a}} \geq 125$ & \\
8-h hemofiltration in early PIRRT & & \\
\hline Ultrafiltrate flow rate (L/hr) & Ciprofloxacin & Levofloxacin \\
\hline 2 & 96 & 98 \\
3 & 95 & 98 \\
4 & 94 & 97 \\
$5^{\mathrm{b}}$ & 93 & 97 \\
6 & 93 & 97 \\
7 & 93 & 97 \\
8 & 93 & 97 \\
9 & 92 & 96 \\
10 & 92 & 96
\end{tabular}

PTA data were from 8-h PIRRT using a $5 \mathrm{~L} / \mathrm{h}$ effluent flow rate (ultrafiltrate flow rate) with blood flow rate of $300 \mathrm{~mL} / \mathrm{min}$. Similar PTA was resulted from 10-h PIRRT

${ }^{\mathrm{a}} \mathrm{MIC}=1 \mathrm{mg} / \mathrm{L}$ for ciprofloxacin and MIC $=2 \mathrm{mg} / \mathrm{L}$ for levofloxacin (susceptibility breakpoint for Pseudomonas aeruginosa)

${ }^{\mathrm{b}}$ Reference flow rate used in this study realization that conventional fluoroquinolone doses do not reliably achieve the pharmacodynamic target of $\mathrm{AUC}_{24 \mathrm{~h}}: \mathrm{MIC} \geq 125$ in infected critically ill patients with or without RRT [36, 45-49]. In a recent report, ciprofloxacin $1600 \mathrm{mg} /$ day was necessary to attain $\mathrm{AUC}_{24 \mathrm{~h}}$ :MIC $\geq 125$ (bacterial susceptibility of MIC $\leq 1 \mathrm{mg} / \mathrm{L}$ ) at a steady state in an obese critically ill patient receiving CRRT [49]. A previous study with 14 critically ill patients with $P$. aeruginosa infection receiving CRRT also reported the commonly recommended ciprofloxacin dose (400 mg q24h) for CRRT [50] was inadequate to attain even a less rigorous pharmacodynamic target $\left(\mathrm{AUC}_{24 \mathrm{~h}}: \mathrm{MIC} \geq 100\right)$ [36]. The present study shows that even the use of conventional doses recommended for normal renal function in patients with PIRRT would yield inadequate drug exposure. However, no clinical studies have been conducted to evaluate the safety of fluoroquinolone doses that are higher than recommended in critically ill patients. Consequently, it is advised that ciprofloxacin and levofloxacin should not be used as empiric monotherapy for serious Gram-negative infections in patients receiving PIRRT due to concerns of suboptimal antibiotic exposure. In situations when fluoroquinolones are to be used in combination with another primary antibiotic, we would recommend the maximal doses, at least $400 \mathrm{mg}$ q8h for ciprofloxacin and $750 \mathrm{mg}$ loading dose, followed by $750 \mathrm{mg}$ q24h post-PIRRT for levofloxacin.

The higher the RRT flow rate, the higher the fluoroquinolone RRT clearance should be, and our findings were consistent with previous studies. The estimated mean fluoroquinolone clearances $(55.0 \mathrm{~mL} / \mathrm{min}$ for ciprofloxacin and $48.3 \mathrm{~mL} / \mathrm{min}$ for levofloxacin with an effluent rate of $83 \mathrm{~mL} / \mathrm{min}$ ) by PIRRT in the present study 
were higher than those reported $(13.3-41.7 \mathrm{~mL} / \mathrm{min}$ for ciprofloxacin and $11.0-27.6 \mathrm{~mL} / \mathrm{min}$ for levofloxacin) in CRRT that used lower effluent flows of $17-30 \mathrm{~mL} / \mathrm{min}$ (Table 5) [30-34, 36, 37]. In contrast, our calculated PIRRT clearances were also lower than those published in IHD with effluent flow rates of $500-600 \mathrm{~mL} / \mathrm{min}[51,52]$. The levofloxacin clearance by PIRRT in this present study was similar to the clearance reported in five patients with extended daily dialysis $(48.8[25.2-72.5] \mathrm{mL} / \mathrm{min}$ as median[range]), another type of PIRRT [27]. However, levofloxacin half-life was shorter in this previous study (34.5 [21.2-47.7] hours as median[range] vs. $52.8+17.0 \mathrm{~h}$ ) because the levofloxacin $\mathrm{CL}_{\mathrm{NR}}$ was higher than that used in this study $(51.0$ [49.0-52.8] $\mathrm{mL} / \mathrm{min}$ as median[range] vs. $24.7+11.7 \mathrm{~mL} / \mathrm{min}$ ) [27]. This levofloxacin $\mathrm{CL}_{\mathrm{NR}}$ in the previous study was reported to be much higher than all of those reported in other published studies with similar patient population receiving CRRT (mean range of 15.0$30.9 \mathrm{~mL} / \mathrm{min}$ ) (Table 5) [31-34].

Sensitivity analyses evaluated the influence of different PIRRT operation settings on PTA of fluoroquinolone dosing regimens. It has been suggested that for PIRRT, "when" to administer a drug relative to PIRRT institution may be a more important factor than "how much" drug to give [14]. Sensitivity analyses indicate that this is the case for a drug with longer half-life that is given infrequently like levofloxacin. For example, PTA of levofloxacin $\mathrm{q} 24 \mathrm{~h}-\mathrm{q} 48 \mathrm{~h}$ dosing regimens differed by up to $20 \%$ in early vs. late PIRRT as shown in Tables 2 and 3. However, ciprofloxacin, which is given more frequently with $\mathrm{q} 8 \mathrm{~h}-\mathrm{q} 12 \mathrm{~h}$ dosing regimens yielded only $1-6 \%$ PTA difference in early vs. late PIRRT (Table 2). PIRRT operating settings vary from institution to institution, and the PIRRT variable that is most varied between institutions is effluent rate. Some centers are more aggressive and use high effluent rates, while others use rates closer to what is seen in CRRT. We assessed the influence of this commonly modified parameter in Table 4. Interestingly, the effluent rate had a surprisingly small influence on PTA rates. Varying effluent rates from 2 to $10 \mathrm{~L} / \mathrm{h}$ (our models used 4 and $5 \mathrm{~L} / \mathrm{h}$ ) for $8-10 \mathrm{~h}$ only changed PTA by $2-4 \%$. This $2-4 \%$ difference caused by effluent flow rates is dwarfed by the change in PTA caused by "when" the dose is given in relation to PIRRT.

This study has some limitations. Simulations were performed under the assumption that patients were adult-sized with negligible renal drug clearance and were characterized with literature-based demographic and pharmacokinetic parameters. The model also incorporated "daily" PIRRT. Thus, our recommendation should be applied to those who match these demographic and pharmacokinetic characteristics and receive daily PIRRT. Any time that MCSs are used to inform antibiotic dosing, clinical validation is warranted. However, in this case, it would appear to be unethical to conduct a fluoroquinolone PIRRT pharmacokinetic trial with the doses that achieved $90 \%$ PTA because these doses are likely to be toxic. We have confidence that the model performed accurately based on the fact that our findings independently corroborate reports that conventionally dosed fluoroquinolones rarely achieve therapeutic targets in critically ill patients, and

Table 5 Modeled fluoroquinolone clearances and half-lives in PIRRT and comparison to pharmacokinetic data in other types of RRT

\begin{tabular}{|c|c|c|c|c|}
\hline \multicolumn{5}{|l|}{ Ciprofloxacin } \\
\hline & PIRRT (present study) & CRRT $[30,31,36,37]$ & EDD & IHD [49] \\
\hline $\mathrm{Q}_{\text {Effluent }}(\mathrm{mL} / \mathrm{min})$ & 83.3 & $17-50^{\mathrm{b}}$ & $N / S$ & 500 \\
\hline $\mathrm{CL}_{R R T}(\mathrm{~mL} / \mathrm{min})$ & $55.0 \pm 13.3^{\mathrm{a}}$ & $13.3-41.7^{b}$ & $N / S$ & 57.2 \\
\hline $\mathrm{CL}_{\text {OFF-RRT }}(\mathrm{mL} / \mathrm{min})$ & $108.3 \pm 48.3^{\mathrm{a}}$ & $102-166^{\mathrm{b}}$ & $N / S$ & $N / R$ \\
\hline $\mathrm{t}_{1 / 2}$ ON-RRT (h) & $8.2 \pm 5.0^{\mathrm{a}}$ & $9.4-13.8^{b}$ & $N / S$ & $3.2 \pm 0.4^{a}$ \\
\hline$t_{1 / 2}$ OFF-RRT (h) & $13.9 \pm 10.5^{\mathrm{a}}$ & N/A & $N / S$ & $5.8 \pm 0.9^{a}$ \\
\hline \multicolumn{5}{|l|}{ Levofloxacin } \\
\hline & PIRRT (present study) & CRRT [31-34] & EDD [27] & $\mathrm{IHD}[50]$ \\
\hline$Q_{\text {Effluent }}(\mathrm{mL} / \mathrm{min})$ & 83.3 & $17-50^{\mathrm{b}}$ & 160 & 600 \\
\hline $\mathrm{CL}_{R R T}(\mathrm{~mL} / \mathrm{min})$ & $48.3+15.0^{\mathrm{a}}$ & $11.0-27.6^{\mathrm{b}}$ & $48.8[25.2-72.5]^{\mathrm{C}}$ & $84.4[61.8-107.6]^{c}$ \\
\hline $\mathrm{CL}_{\text {OFF-RRT }}(\mathrm{mL} / \mathrm{min})$ & $24.7+11.7^{a}$ & $15.0-30.9^{b}$ & $51.0[49.0-52.8]^{c}$ & $37.0[12.8-42.7]^{c}$ \\
\hline $\mathrm{t}_{1 / 2}$ ON-RRT $(\mathrm{h})$ & $16.7+6.0^{\mathrm{a}}$ & $8.3-45.9^{b}$ & $10.3[10.0-10.6]^{c}$ & $N / R$ \\
\hline$t_{1 / 2}$ OFF-RRT $(h)$ & $52.8+17.0^{a}$ & N/A & $34.5[21.2-47.7]^{c}$ & $34.4[28.4-39.3]^{c}$ \\
\hline
\end{tabular}

Clearance and half-life data in PIRRT were from on and off 8-h hemodialysis PIRRT

N/A not applicable, N/S not studied, N/R not reported, PIRRT prolonged intermittent renal replacement therapy, CRRT continuous renal replacement therapy, EDD extended daily dialysis, IHD intermittent hemodialysis, $Q_{\text {Effluent }}$ effluent flow rate, $C L_{R R T}$ drug clearance by renal replacement therapy, $C L_{O F F-R R T}$ drug clearance off RRT, $T_{1 / 2}$ ON-RRT half-life during RRT, $T_{1 / 2}$ OFF-RRT half-life off-RRT

${ }^{\mathrm{a}}$ Mean \pm SD

${ }^{\mathrm{b}}$ Mean ranges reported from the references

cMedian [range] 
like those reports [36, 45-49], we also do not recommend their use as empiric monotherapy in this population receiving PIRRT due to the concern for suboptimal serum concentration attainment that contributes to increasing bacterial resistance. Although smaller levofloxacin doses can be used to treat S. pneumonia in PIRRT patients based on our data, the maximal FDA-approved fluoroquinolone dose should be used as empiric treatment for infected critically ill patients with PIRRT as combination therapy when necessary. Even as adjunctive therapy, fluoroquinolones are associated with potentially life-threatening cardiovascular and CNS toxicities [24-26]. Thus, close monitoring for cardiovascular- and neurotoxicity should be followed when this fluoroquinolone dosing is used to treat these vulnerable patients.

\section{Conclusions}

In silico trials using MCS are useful and may be the only alternative to guide appropriate antibiotic dosing where pharmacokinetic data are absent and clinical trials are not likely to be conducted. This simulation study indicated that none of the conventional ciprofloxacin and levofloxacin dosing regimens are likely to be efficacious as empiric treatment for Gram-negative infections caused by $P$. aeruginosa in critically ill patients with daily PIRRT. Pharmacodynamic target attainment during the initial $72 \mathrm{~h}$ required up to three to fourfold higher fluoroquinolone doses than the maximally approved doses in these patients. Use of these extreme dosing regimens cannot be recommended because of concerns of fluoroquinolone-associated toxicity in these vulnerable patients. These in silico simulations support rational dosing decision for clinicians treating infected patients receiving PIRRT and should be used until clinical pharmacokinetic trials are conducted in this population.

\section{Additional files}

Additional file 1: Equations to calculate fluoroquinolone serum concentrations using a one-compartmental model. Mathematical equations used to generate fluoroquinolone serum concentration-time profiles in virtual patients receiving PIRRT are described. (PDF $378 \mathrm{~kb}$ )

Additional file 2: Probability of target attainment of fluoroquinolones in virtual patients with different PIRRT settings. The tables report probability of target attainment (PTA) of selected fluoroquinolone regimens in virtual patients with other PIRRT settings that are not included in the main text. The other PIRRT settings include 8-h hemofiltration with an ultrafiltrate flow rate of $5 \mathrm{~L} / \mathrm{h}, 10-\mathrm{h}$ hemodialysis with a dialysate flow rate of $4 \mathrm{~L} / \mathrm{h}$, and $10-\mathrm{h}$ hemofiltration with an ultrafiltrate flow rate of $4 \mathrm{~L} / \mathrm{h}$. The first three tables describe PTA of selected ciprofloxacin and levofloxacin dosing regimens for Gram-negative infection with $P$. aeruginosa in virtual patients, while the other three tables illustrate PTA of selected levofloxacin dosing regimens for Gram-positive infections with S. pneumoniae. (PDF 235 kb)

Additional file 3: Probability of target attainment of fluoroquinolones at different MICs in virtual patients with different PIRRT settings. The figures illustrate probability of target attainment (PTA) of selected fluoroquinolone regimens at different MICs in virtual patients with other PIRRT settings that are not included in the main manuscript. The other PIRRT settings include 8-h hemofiltration with an ultrafiltrate flow rate of $5 \mathrm{~L} / \mathrm{h}, 10$-h hemodialysis with a dialysate flow rate of $4 \mathrm{~L} / \mathrm{h}$, and 10-h hemofiltration with an ultrafiltrate flow rate of $4 \mathrm{~L} / \mathrm{h}$. The first three figures describe PTA of selected ciprofloxacin and levofloxacin dosing regimens at different MICs for Gram-negative infection with $P$. aeruginosa in virtual patients, while the last figure depicts PTA of selected levofloxacin dosing regimens for Gram-positive infections with S. pneumoniae. (PDF $214 \mathrm{~kb}$ )

\section{Abbreviations}

$\mathrm{AUC}_{24 \mathrm{~h}}$, 24-h area under the curve; $\mathrm{CL}_{\mathrm{HD}}$, transmembrane clearance in hemodialysis; $\mathrm{CL}_{\mathrm{HF}}$, transmembrane clearance in hemofiltration; $\mathrm{CL}_{\mathrm{NR}}$, non-renal clearance; CNS, central nervous system; CRRT, continuous renal replacement therapy; IHD, intermittent hemodialysis; MCS, monte carlo simulations; MIC, minimum inhibitory concentration; PIRRT, prolonged intermittent renal replacement therapy; PTA, probability of target attainment; $Q_{d}$, dialysate flow rate; $Q_{\text {plasma }}$ plasma flow rate; Q replacement, replacement fluid flow rate; $Q_{u f}$ ultrafiltrate flow rate; RRT, renal replacement therapy; SA, saturation coefficient; SC, sieving coefficient; $V_{d}$, volume of distribution

\section{Funding}

This study was funded by NxStage Medical, Inc.

\section{Authors' contributions}

SJL and BAM contributed to the conception and design, data collection, and analysis and interpretation of the data. WC and AS contributed to data acquisition, analysis, and interpretation. SJL and BAM drafted the manuscript. All authors were involved in revising it critically for important intellectual content. All authors read and approved the final approval of the present version of the manuscript to be published.

\section{Authors' information}

$\mathrm{SJL}$ is an assistant professor at the Department of Pharmacy Practice, University of Findlay College of Pharmacy, 1000 N., Main Street, Findlay, Ohio, 45840, USA. WC works at the Pharmacy Faculty at Siam University, Bangkok, Thailand. AS is a Critical Care Nephrology Research Fellow at the Department of Clinical Pharmacy, University of Michigan College of Pharmacy, 428 Church Street, Ann Arbor, Michigan, 48109, USA. BAM is a professor and an associate dean of Academic Affairs at the Department of Clinical Pharmacy, University of Michigan College of Pharmacy, 428 Church Street, Ann Arbor, Michigan, 48109, USA

\section{Competing interests}

Drs. Mueller and Lewis have received grant funding from NxStage Medical, Inc., to support this work.

Dr. Mueller has served on NxStage Medical, Inc.'s speaker's bureau. Portions of this paper were accepted as abstracts and were presented as a poster presentation at Acute Kidney Injury Continuous Renal Replacement Therapy 2016 International Conference, San Diego, CA, on February 16-19, 2016.

\section{Author details}

${ }^{1}$ Department of Pharmacy Practice, University of Findlay College of Pharmacy, 1000 N. Main Street, Findlay, OH 45840, USA. ² Pharmacy Faculty, Siam University, Bangkok, Thailand. ${ }^{3}$ Department of Clinical Pharmacy, University of Michigan College of Pharmacy, 428 Church Street, Ann Arbor, MI 48109, USA.

Received: 4 April 2016 Accepted: 21 July 2016

Published online: 07 September 2016

References

1. Kumar VA, Craig M, Depner TA, Yeun JY. Extended daily dialysis: a new approach to renal replacement for acute renal failure in the intensive care unit. Am J Kidney Dis. 2000;36:294-300.

2. Bellomo R, Baldwin I, Fealy N. Prolonged intermittent renal replacement therapy in the intensive care unit. Crit Care Resusc. 2002;4:281-90.

3. Fliser D, Kielstein JT. Technology insight: treatment of renal failure in the intensive care unit with extended dialysis. Nat Clin Practi Nephrol. 2006;2:32-9. 
4. Gashti CN, Salcedo S, Robinson V, Rodby RA. Accelerated venovenous hemofiltration: early technical and clinical experience. Am J Kidney Dis. 2008:51:804-10.

5. Bogard KN, Peterson NT, Plumb TJ, Erwin MW, Fuller PD, Olsen KM. Antibiotic dosing during sustained low-efficiency dialysis: special considerations in adult critically ill patients. Crit Care Med. 2011;39:560-70.

6. Duran PA, Concepcion LA. Survival after acute kidney injury requiring dialysis: long-term follow up. Hemodial Int. 2014;18 Suppl 1:S1-6.

7. Zhang L, Yang J, Eastwood GM, Zhu G, Tanaka A, Bellomo R. Extended daily dialysis versus continuous renal replacement therapy for acute kidney injury: a meta-analysis. Am J Kidney Dis. 2015;66:322-30.

8. Roberts JA, Mehta RL, Lipman J. Sustained low efficiency dialysis allows rational renal replacement therapy, but dose it allow rational drug dosing? Crit Care Med. 2011;39:602-3.

9. Kollef MH, Sherman G, Ward S, Fraser VJ. Inadequate antimicrobial treatment of infections: a risk factor for hospital mortality among critically ill patients. Chest. 1999;115:462-74.

10. Jamal JA, Mueller BA, Choi GY, Lipman J, Roberst JA. How can we ensure effective antibiotic dosing in critically ill patients receiving different types of renal replacement therapy? Diagn Microbiol Infect Dis. 2015;82:92-103.

11. Vincent JL, Rello J, Marshall J, Silva E, Anzueto A, Martin CD, et al. International study of the prevalence and outcomes of infection in intensive care units. JAMA. 2009;302:2323-9.

12. Zelenitsky SA, Ariano RE, McCrae ML, Vercaigne LM. Initial vancomycin dosing protocol to achieve therapeutic serum concentrations in patients undergoing hemodialysis. Clin Infect Dis. 2012;55:527-33.

13. Nehus EJ, Mouksassi S, Vinks AA, Goldstein S. Meropenem in children receiving continuous renal replacement therapy: clinical trial simulations using realistic covariates. J Clin Pharmacol. 2014:54:1421-8.

14. Mueller BA, Scoville BA. Adding to the armamentarium: antibiotic dosing in extended dialysis. Clin J Am Soc Nephrol. 2012;7:373-5.

15. LaPlante KL, Rybak MJ, Tsuji B, Lodise TP, Kaatz GW. Fluoroquinolone resistance in Streptococcus pneumoniae: area under the concentration-time curve/MIC ratio and resistance development with gatifloxacin, gemifloxacin, levofloxacin, and moxifloxacin. Antimicrob Agents Chemother. 2007;51:1315-20.

16. Sader HS, Farrell DJ, Flamm RK, Jones RN. Antimicrobial susceptibility of Gram-negative organisms isolated from patients hospitalized in intensive care units in United States and European hospitals (2009-2011). Diagn Microbiol Infect Dis. 2014;78:443-8.

17. Itokazu GS, Quinn JP, Bell-Dixon C, Kahan FM, Weinstein RA. Antimicrobial resistance rates among aerobic Gram-negative bacilli recovered from patients in intensive care units: evaluation of a national postmarketing surveillance program. Clin Infect Dis. 1996;23:779-84.

18. Zhanel GG, DeCorby M, Laing N, Weshnoweski B, Vashisht R, Tailor F, et al. Antimicrobial-resistant pathogens in intensive care units in Canada: results of the Canadian National Intensive Care Unit (CAN-ICU) study, 2005-2006. Antimicrob Agents Chemother. 2008;52:1430-7.

19. Hooper DC. Fluoroquinolone resistance among Gram-positive cocci. Lancet Infect Dis. 2002;2:530-8.

20. Neuhauser MM, Weinstein RA, Rydman R, Danziger LH, Karam G, Quinn JP. Antibiotic resistance among Gram-negative bacilli in US intensive care units: implications for fluoroquinolone use. JAMA. 2003;289:885-8.

21. Drusano GL, Preston SL, Fowler C, Corrado M, Weisinger B, Kahn J. Relationship between fluoroquinolone area under the curve: minimum inhibitory concentration ratio and the probability of eradication of the infecting pathogen in patients with nosocomial pneumonia. J Infect Dis. 2004;189:1590-7.

22. Forrest A, Nix DE, Ballow CH, Goss TF, Birmingham MC, Schentag JJ. Pharmacodynamics of intravenous ciprofloxacin in seriously ill patients. Antimicrob Agents Chemother. 1993;37:1073-81.

23. Ambrose PG, Grasela DM, Grasela TH, Passarell J, Mayer HB, Pierce PF. Pharmacodynamics of fluoroquinolones against Streptococcus pneumonia in patients with community-acquired respiratory tract infections. Antimicrob Agents Chemother. 2001;45:2793-7.

24. Rubinstein E, Camm J. Cardiotoxicity of fluroquinolones. J Antimicrob Chemother. 2002:49:593-6.

25. Liu HH. Safety profile of the fluoroquinolones: focus on levofloxacin. Clin Infect Dis. 2005;41 Suppl 2:S144-157.

26. Stahlmann R. Lode HM Risks associated with the therapeutic use of fluoroquinolones. Expert Opin Drug Saf. 2013;12:497-505.

27. Czock D, Hüsig-Linde C, Langhoff A, Schöpke T, Hafer C, de Groot K, et al. Pharmacokinetics of moxifloxacin and levofloxacin in intensive care unit patients who have acute renal failure and undergo extended daily dialysis. Clin J Am Soc Nephrol. 2006;1:1263-8.

28. Mei JP, Ali-Moghaddam A, Mueller BA. Survey of pharmacists' antibiotic dosing recommendations for sustained low-efficiency dialysis. Int J Clin Pharm. 2015;38:127-34.

29. Davies SP, Azadian BS, Kox WJ, Brown EA. Pharmacokinetics of ciprofloxacin and vancomycin in patients with acute renal failure treated by continuous haemodialysis. Nephrol Dial Transplant. 1992;7:848-54.

30. Wallis SC, Mullany DV, Lipman J, Rickard CM, Daley PJ. Pharmacokinetics of ciprofloxacin in ICU patients on continuous veno-venous haemodiafiltration. Intensive Care Med. 2001;27:665-72.

31. Malone RS, Fish DN, Abraham E, Teitelbaum I. Pharmacokinetics of levofloxacin and ciprofloxacin during continuous renal replacement therapy in critically ill patients. Antimicrob Agents Chemother. 2001;45:2949-54.

32. Traunmüller F, Thalhammer-Scherrer R, Locker GJ, Losert H, Schmid R, Staudinger $T$, et al. Single-dose pharmacokinetics of levofloxacin during continuous veno-venous haemofiltration in critically ill patients. J Antimicrob Chemother. 2001;47:229-31.

33. Hansen $E$, Bucher $M$, Jakob W, Lemberger $P$, Kees F. Pharmacokinetics of levofloxacin during continuous veno-venous hemofiltration. Intensive Care Med. 2001;27:371-5.

34. Guenter SG, Iven H, Boos C, Bruch HP, Muhl E. Pharmacokinetics of levofloxacin during continuous venovenous hemodiafiltration and continuous venovenous hemofiltration in critically ill patients. Pharmacotherapy. 2002;22:175-83.

35. Spooner AM, Deegan C, D'Arcy DM, Gowing CM, Donnelly MB, Corrigan OI. An evaluation of ciprofloxacin pharmacokinetics in critically ill patients undergoing continuous veno-venous haemodiafiltration. BMC Clin Pharmacol. 2011. doi:10.1186/1472-6904-11-11.

36. Shotwell MS, Madonia PN, Connor MJ, Made M, Salem C, Aduroja OA, et al. Ciprofloxacin pharmacokinetics in critically ill patients receiving concomitant continuous venovenous hemodialysis. Am J Kidney Dis. 2015;66:173-5.

37. Troyanov S, Cardinal J, Geadah D, Parent D, Courteau S, Caron S, et al. Solute clearances during continuous venovenous haemofiltration at various ultrafiltration flow rates using Multiflow-100 and HF1000 filters. Nephrol Dial Transplant. 2003;18:961-6.

38. Gashti CN, Rodby RA, Huang Z, Gao D, Zhang W. Effects of high blood flow and high pre-dilution replacement fluid rates on small solute clearances in hemofiltration. Blood Purif. 2011;32:266-70.

39. Lewis SJ, Kays MB, Mueller BA. Use of Monte Carlo simulations to determine optimal carbapenem dosing in critically ill patients receiving prolonged intermittent renal replacement therapy. J Clin Pharmcol. 2016. doi:10.1002/ jcph.727. [Epub ahead of print].

40. Cipro ${ }^{\oplus}$ I.V. [ciprofloxacin] [package insert], Wayne. NJ: Bayer HealthCare Pharmaceuticals, Inc.; 2011.

41. Levaquin ${ }^{\oplus}$ (levofloxacin) [pkg insert], Paritan. NJ: Philadelphia. PA: OrthoMcNeil-Janssen Pharmaceuticals, Inc.; 2008.

42. Shorr AF. Review of studies of the impact on Gram-negative bacterial resistance on outcomes in the intensive care unit. Crit Care Med. 2009;37:1463-9.

43. Clinical and Laboratory Standards Institute. Performance standards for antimicrobial susceptibility testing; twenty fourth informational supplement. CLSI document M100-S24. Wayne: Clinical and Laboratory Standards Institute; 2014.

44. Brunet S, Leblanc M, Geadah D, Parent D, Courteau S, Cardinal J. Diffusive and convective solute clearances during continuous renal replacement therapy at various dialysate and ultrafiltration flow rates. Am J Kidney Dis. 1999;34:486-92

45. Kiser TH, Hoody DW, Obritsch MD, Wegzyn CO, Bauling PC, Fish DN. Levofloxacin pharmacokinetics and pharmacodynamics in patients with severe burn injury. Antimicrob Agents Chemother. 2006;50(6):1937-45.

46. Burgess DS, Hall II RG. Simulated comparison of the pharmacodynamics of ciprofloxacin and levofloxacin against Pseudomonas aeruginosa using pharmacokinetic data from healthy volunteers and 2002 minimum inhibitory concentration data. Clin Ther. 2007;29:1421-7.

47. Khachman D, Conil JM, Georges B, Saivin S, Houin G, Toutain PL, et al. Optimizing ciprofloxacin dosing in intensive care unit patients through the use of population pharmacokinetic-pharmacodynamic analysis and Monte Carlo simulations. J Antimicrob Chemother. 2011;66:1798-809.

48. Zelenitsky SA, Ariano RE, Zhanel GG. Pharmacodynamics of empirical antibiotic monotherapies for an intensive care unit (ICU) population based on Canadian surveillance data. J Antimicrob Chemother. 2011;66:343-9. 
49. Utrup TR, Mueller EW, Healy DP, Callcut RA, Peterson JD, Hurford WE. Highdose ciprofloxacin for serious Gram-negative infection in an obese, critically ill patient receiving continuous venovenous hemodiafiltration. Ann Pharmacother. 2010:44:1660-4.

50. Aronoff GR, Bennett WM, Berns JS, Brier ME, Kasbekar N, Mueller BA, et al. Drug prescribing in renal failure: dosing guidelines for adults and children. 5th ed. Philadelphia: American College of Physicians; 2007.

51. Boelaert J, Valche Y, Schurgers M, Daneels R, Rosseneu M, Rosseel MT, et al. The pharmacokinetics of ciprofloxacin in patients with impaired renal function. J Antimicrob Chemother. 1985;16:87-93.

52. Sowinski KM, Lucksiri A, Kays MB, Scott MK, Mueller BA, Hamburger RJ. Levofloxacin pharmacokinetics in ESRD and removal by the cellulose acetate high performance-210 hemodialyzer. Am J Kidney Dis. 2003;42:342-9.

Submit your next manuscript to BioMed Central and we will help you at every step:

- We accept pre-submission inquiries

- Our selector tool helps you to find the most relevant journal

- We provide round the clock customer support

- Convenient online submission

- Thorough peer review

- Inclusion in PubMed and all major indexing services

- Maximum visibility for your research

Submit your manuscript at www.biomedcentral.com/submit
Biomed Central 